\title{
Association of dietary intake of folate and MTHFR genotype with breast cancer risk
}

\author{
Z.G. Wang ${ }^{1}$, W. Cui ${ }^{2}$, L.F. Yang ${ }^{2}$, Y.Q. Zhu ${ }^{3}$ and W.H. Wei ${ }^{2}$ \\ ${ }^{1}$ Medical Image Center, Xinxiang Central Hospital, Xinxiang, China \\ ${ }^{2}$ Special-Needed Hospital Ward, Xinxiang Central Hospital, Xinxiang, China \\ ${ }^{3}$ Health Check Centre, Xinxiang Central Hospital, Xinxiang, China \\ Corresponding author: Z.G. Wang \\ E-mail:wzg_xch@163.com
}

Genet. Mol. Res. 13 (3): 5446-5451 (2014)

Received June 24, 2013

Accepted December 3, 2013

Published July 24, 2014

DOI http://dx.doi.org/10.4238/2014.July.24.24

\begin{abstract}
We conducted a hospital-based case-control study to investigate the associations of dietary intake of folate and MTHFR C677T and A1298C polymorphisms with breast cancer in a Chinese population. A 1:1-matched case-control study was conducted. Two hundred and thirty patients who were newly diagnosed and histologically confirmed breast cancer and 230 controls were enrolled from Xinxiang Central Hospital. Folate intake was calculated by standard portion size and relative size for each food item in the questionnaire. Genotyping of MTHFR C677T and A1298C was performed by PCR-RFLP. MTHFR $677 \mathrm{TT}(\mathrm{OR}=2.26,95 \% \mathrm{CI}=1.09-4.87, \mathrm{P}=0.02)$ and $\mathrm{T}$ allele $(\mathrm{OR}=$ $1.40,95 \% \mathrm{CI}=1.03-1.90, \mathrm{P}=0.03)$ had an increased risk of laryngeal cancer when compared with the CC genotype. We found any interaction between MTHFR C677T and folate intake $(\mathrm{P}$ for interaction $=0.02)$. In conclusion, our study demonstrated that MTHFR C677T polymorphism and folate are associated with risk of breast cancer.
\end{abstract}

Key words: Folate; MTHFR; Polymorphism; Breast cancer 


\section{INTRODUCTION}

Dietary folate and vitamins have an important role in one-carbon metabolism, which is essential for DNA methylation, synthesis and repair (Ulrich, 2005). Low dietary folate intake has been associated with risk of various cancers, such as colorectal cancer, pancreatic cancer, prostate cancer and gastric cancer (Bassett et al., 2013; Lin et al., 2013; Collin, 2013; Gao et al., 2013). Recently, several studies reported a protective effect of folate intake on breast cancer risk (Liu et al., 2013; Yang et al., 2013; Islam et al., 2013). However, evidence from two recent studies have indicated an inverse association (Ericson et al., 2007; Maruti et al., 2009a), and some other studies have shown that the reduced risk only exists in certain populations, such as women with high levels of alcohol intake or premenopausal Chinese women (Levi et al., 2001; Shrubsole et al., 2011).

Previous studies have suggested an association between altered diet and tumorigenesis (Ulrich, 2005), and thus, inherited genetic variation in genes involved with nutrient-metabolizing enzymes could influence the development of cancer. Methylenetetrahydrofolate reductase (MTHFR) is a key enzyme in folate metabolism and it catalyzes the irreversible reduction of 5,10-methylenetetrahydrofolate, where it is converted to 5-methyl-THFR.

Two common MTHFR gene polymorphisms, C677T and A1298C, have been widely discussed (de Cássia et al., 2012; Wu et al., 2012). Many studies have examined the association between MTHFR gene polymorphisms and risk of breast cancer, and suggested that MTHFR C677T and A1298C polymorphisms are associated with an increased or decreased risk of breast cancer (Le Marchand et al., 2004; Rossi et al., 2006; Yu and Chen, 2012; Jiao and $\mathrm{Li}, 2013)$. Previous studies reported the association between the MTHFR genotype polymorphisms and folate intake and risk of breast cancer (Alshatwi, 2010; Sangrajrang et al., 2010; Lajin et al., 2012), but the results are inconsistent. In our study, we conducted a hospitalbased case-control study to investigate the associations of dietary intake of folate and MTHFR C677T and A1298C polymorphisms with breast cancer in a Chinese population.

\section{MATERIAL AND METHODS}

\section{Subjects}

Our study recruited 230 patients who were newly diagnosed and histologically confirmed breast cancer between March 2009 and October 2010 at Xinxiang Central Hospital. Patients with a history of cancer were excluded from our study. Control subjects were selected from subjects for regular health check-up at the same hospital during the same period. All the control subjects matched cases by age (within 5 years). All cases and controls signed informed consent, and the study protocol was approved by the Ethics Committee of Xinxiang Central Hospital.

The demographic characteristics of cases and control subjects were collected by a face to face interview using a structured questionnaire. The medical history, family history of cancer and reproductive factors were collected from medical records. The folate intake was calculated from a food-frequency questionnaire with 80 food terms.

Intake of folate were computed by multiplying frequency by standard portion size and relative size for each food item in the questionnaire, and then the sum of all folate intake from various foods/food groups was calculated as the total folate intake. 


\section{Genotype of polymorphisms}

The participants were asked to provide $5 \mathrm{~mL}$ peripheral blood samples, which were stored at $-20^{\circ} \mathrm{C}$. Genomic DNA was extracted from peripheral blood samples using QIAGEN FlexiGene DNA kits according to the manufacturer protocol. Genotyping of MTHFR C677T and A1298C genetic polymorphisms was determined using polymerase chain reaction (PCR)-restriction fragment length polymorphism. Primers and probes of MTHFR C677T and A1298C for PCR amplification were designed by the Sequenom ${ }^{\circledR}$ Assay Design 3.1 software $\left(\right.$ Sequenom $\left.^{\circledR}\right)$. PCR for C677T was performed with the primers forward 5'-CGTGGCTCCTGCGTTTCC-3' and reverse 5'-GAGCCGGCCACAGGCAT-3'; PCR for A1298C was performed using the primers forward 5'-CAAATCTGAGGGAGCTGAGT-3' and reverse 5'-CAGATAAGTGGCAGTACAGA-3'. The PCR conditions were as follows: initial denaturation at $95^{\circ} \mathrm{C}$ for $5 \mathrm{~min}$, followed by 30 cycles of $94^{\circ} \mathrm{C}$ for $2 \mathrm{~min}$, annealing at $64^{\circ} \mathrm{C}$ for $30 \mathrm{~s}$, extension at $72^{\circ} \mathrm{C}$ for $90 \mathrm{~s}$, and a final extension at $72^{\circ} \mathrm{C}$ for $10 \mathrm{~min}$. Cases and controls $(10 \%)$ were randomly selected to repeat analysis to confirm consistency, and the consistency rate was $100 \%$.

\section{Statistical analysis}

All statistical analyses were performed using Stata version 8 (Stata, College Station, TX, USA). Continuous variables are reported as means \pm standard deviation (SD), and categorical variables are reported as frequencies $(\mathrm{N})$ and percentages. The Student $t$-test and the $\chi^{2}$ test were used to assess differences between cases and controls with regard to demographic characteristics. A goodness-of-fit $\chi^{2}$ test was used to evaluate the Hardy-Weinberg equilibrium (HWE) in controls. Conditional logistic regression was performed to analyze the association between dietary intake of folate and MTHFR C677T and A1298C polymorphisms with breast cancer and breast cancer risk, with the estimated ORs and their 95\% confidence interval (CI) after adjusting for potential confounding variables. Stratified analyses were used to evaluate the potential modifying effect of folate on breast cancer risk with MTHFR genotypes. P less than 0.05 was considered to be significance.

\section{RESULTS}

The demographic and clinical characteristics of breast cancer cases and controls are shown in Table 1. The mean age of patients and controls were $48.6 \pm 9.7$ and $48.2 \pm 8.8$ years, respectively. The breast cancer cases were more likely to be younger at menarche, older at first live birth, more first-degree relatives, and higher folate intake. However, we did not find that live birth and menopausal status were associated with risk of breast cancer.

For the MTHFR gene, there was significant difference between genotype distributions of MTHFR C677T between cases and controls. Subjects carrying MTHFR 677TT (OR $=2.26,95 \% \mathrm{CI}=1.09-4.87, \mathrm{P}=0.02)$ and $\mathrm{T}$ allele $(\mathrm{OR}=1.40,95 \% \mathrm{CI}=1.03-1.90, \mathrm{P}=0.03)$ had an increased risk of laryngeal cancer when compared with the $\mathrm{CC}$ genotype. However, we did not find significant difference between the MTHFR A1298C polymorphism and risk of breast cancer. 


\begin{tabular}{|c|c|c|c|c|c|c|}
\hline & Cases & $\%$ & Controls & $\%$ & $t$ or $\chi^{2}$ & $\mathrm{P}$ value \\
\hline Age (years, mean \pm SD) & $47.5 \pm 8.5$ & & $47.3 \pm 8.6$ & & 0.35 & 0.37 \\
\hline Age at menarche (years) & $12.6 \pm 1.7$ & & $12.9 \pm 1.8$ & & 2.5 & 0.005 \\
\hline Age at first live birth (years) & $26.2 \pm 6.7$ & & $23.6 \pm 7.1$ & & 5.6 & $<0.001$ \\
\hline \multicolumn{7}{|l|}{ Menopausal status } \\
\hline Premenopausal & 198 & 45.5 & 183 & 42.1 & \multirow[t]{2}{*}{1.05} & \multirow[t]{2}{*}{0.31} \\
\hline Postmenopausal & 237 & 54.5 & 252 & 57.9 & & \\
\hline \multicolumn{7}{|c|}{ Breast cancer in first-degree relatives } \\
\hline No & 406 & 93.3 & 433 & 99.5 & \multirow[t]{2}{*}{24.4} & \multirow[t]{2}{*}{$<0.001$} \\
\hline Yes & 29 & 6.7 & 2 & 0.5 & & \\
\hline Folate intake ( $\mu \mathrm{g} /$ day $)$ & $511.5 \pm 94.3$ & & $516.5 \pm 104.2$ & & 0.74 & 0.23 \\
\hline Vitamin $B_{6}(\mathrm{mg} /$ day) & $0.89 \pm 0.26$ & & $0.89 \pm 0.28$ & & 1.09 & 0.14 \\
\hline Vitamin $B_{12}(\mu \mathrm{g} /$ day $)$ & $7.1 \pm 3.5$ & & $7.7 \pm 4.6$ & & 2.17 & 0.02 \\
\hline \multicolumn{7}{|l|}{ MTHFR C665T } \\
\hline $\mathrm{CC}$ & 139 & 31.9 & 168 & 38.6 & \multirow[t]{3}{*}{6.36} & \multirow[t]{3}{*}{0.04} \\
\hline $\mathrm{CT}$ & 216 & 49.7 & 209 & 48.1 & & \\
\hline $\mathrm{TT}$ & 80 & 17.4 & 58 & 13.3 & & \\
\hline \multicolumn{7}{|l|}{ MTHFR C677T } \\
\hline $\mathrm{CC}$ & 250 & 57.5 & 255 & 58.6 & \multirow[t]{3}{*}{0.14} & \multirow[t]{3}{*}{0.93} \\
\hline $\mathrm{CT}$ & 153 & 35.2 & 150 & 34.5 & & \\
\hline TT & 32 & 7.3 & 30 & 6.9 & & \\
\hline \multicolumn{7}{|l|}{ MTHFR A1298C } \\
\hline AA & 206 & 47.4 & 214 & 49.3 & \multirow[t]{3}{*}{0.36} & \multirow[t]{3}{*}{0.84} \\
\hline $\mathrm{AC}$ & 176 & 40.5 & 172 & 39.5 & & \\
\hline $\mathrm{CC}$ & 53 & 12.1 & 49 & 11.2 & & \\
\hline
\end{tabular}

The associations of MTHFR C677T genotypes and folate intake with breast cancer risk are presented in Table 2, after stratifying by the potential risk factors. In terms of low intake of folate, MTHFR 677TT genotype (adjusted $\mathrm{OR}=2.73,95 \% \mathrm{CI}=1.31-5.68, \mathrm{P}=0.01$ ) and $\mathrm{T}$ allele (adjusted $\mathrm{OR}=1.65,95 \% \mathrm{CI}=1.14-2.28, \mathrm{P}=0.03$ ) were associated with higher risk of breast cancer, and the association appeared lower among subjects with moderate intake of folate and MTHFR 677TT genotype (adjusted $\mathrm{OR}=1.92,95 \% \mathrm{CI}=1.01-2.35, \mathrm{P}=0.04$ ). However, no significant association was found in subjects with high intake of folate. Moreover, we found any interaction between MTHFR C677T and folate intake ( $\mathrm{P}$ for interaction $=0.02$ ).

\begin{tabular}{|c|c|c|c|}
\hline Dietary intake & MTHFR C665T & OR $(95 \% \mathrm{CI})$ & $P$ value \\
\hline \multirow{4}{*}{$\begin{array}{l}\text { Vitamin } B_{6} \\
\text { Low }(<0.6 \mathrm{mg} / \text { day })\end{array}$} & & & \\
\hline & $\mathrm{CC}$ & - & \\
\hline & CT & $1.35(0.97-1.74)$ & 0.15 \\
\hline & TT & $1.87(1.29-2.77)$ & 0.01 \\
\hline \multirow[t]{3}{*}{ Moderate $(0.6-1.0 \mathrm{mg} /$ day $)$} & $\mathrm{CC}$ & - & \\
\hline & CT & $1.26(0.91-1.62)$ & 0.26 \\
\hline & TT & $1.58(1.03-2.49)$ & 0.03 \\
\hline \multirow[t]{3}{*}{ High $(>1.0 \mathrm{mg} /$ day $)$} & $\mathrm{CC}$ & - & \\
\hline & CT & $1.11(0.82-1.47)$ & 0.38 \\
\hline & TT & $1.42(0.93-2.36)$ & 0.17 \\
\hline
\end{tabular}

\section{DISCUSSION}

Reports regarding the association of folate metabolism and changes in MTHFR activity with breast cancer are conflicting (Alshatwi, 2010; Sangrajrang et al., 2010; Lajin et al., 
2012). The present study indicated that there was significant association between MTHFR C677T polymorphism and folate intake and risk of breast cancer, and we found a significant interaction between folate intake and MTHFR C677T polymorphism. We found no association between MTHFR A1298C polymorphism and breast cancer risk. Our findings are consistent with previous studies on the association between variants of MTHFR gene and folate and risk of breast cancer (Gao et al., 2009; Alshatwi, 2010; Hosseini et al., 2011; de Cássia Carvalho et al., 2012; Diakite et al., 2012; Lajin et al., 2012; Wu et al., 2012).

MTHFR is a critical gene for one-carbon and folate metabolism, and plays an important role in DNA synthesis or to homocysteine remethylation (Baylin et al., 2005; Kim, 2006; Koppen et al., 2010; Nikbakht et al., 2012). Reduced activity of MTHFR can interfere with the 5-methyletrahydrofolate pathway, which leads to elevated levels of the MTHFR substrate 5,10-methylenetetrahydrofolate and reduced levels of 5-methyletrahydrofolate (Baylin, 2005; Koppen et al., 2010). Therefore, the polymorphisms of MTHFR could alter the folate metabolism, and change the methionine synthesis toward DNA synthesis and repair. Previous several studies have reported that the MTHFR C677T is associated with increased risk of breast cancer (Gershoni-Baruch et al., 2000; Ergul et al., 2003; Maruti et al., 2009b), but some others indicated no association between MTHFR C677T and breast cancer risk (Vaĭner et al., 2010; de Cássia Carvalho et al., 2012). The inconsistency of findings on that association may be explained by differences in population background, source of control subjects, and sample size.

It is reported that folate is able to prevent the development of tumors before established preneoplastic lesions, but it could improve tumorigenesis once lesions have been established (Lin et al., 2008). Although increased folate intake may be good for a population deficient in this nutrient, increased intake in women with already-sufficient levels of folate may provide no further benefit or actually be harmful. Several previous studies did not report a significant association with breast cancer risk (Vaĭner et al., 2010; Islam et al., 2013; Liu et al., 2013), which is in line with our results. The results indicated that folate intake could not play a protective role in breast cancer for women who had a nutritional deficiency.

There were several limitations to our study. Firstly, cases were selected in one hospital. Therefore, the selection bias could not be avoided. Secondly, some factors could have influence on the risk of breast cancer, such as clinical status and other genetic factors as well as ethnicities. However, these factors were not included in our analysis. Therefore, large multicenter studies with different ethnicities are warranted to further investigate the impact of folate intake and MTHFR polymorphism on the risk of breast cancer.

In conclusion, our study demonstrated that MTHFR C677T polymorphism and folate are associated with risk of breast cancer, indicating that this nutrient has a role in the development of breast cancer. Further large sample studies are greatly needed to confirm this association.

\section{REFERENCES}

\footnotetext{
Alshatwi AA (2010). Breast cancer risk, dietary intake, and methylenetetrahydrofolate reductase (MTHFR) single nucleotide polymorphisms. Food Chem. Toxicol. 48: 1881-1885.

Bassett JK, Severi G, Hodge AM, Baglietto L, et al. (2013). Dietary intake of B vitamins and methionine and colorectal cancer risk. Nutr. Cancer 65: 659-667.

Baylin SB (2005). DNA methylation and gene silencing in cancer. Nat. Clin. Pract. Oncol. 2 (Suppl 1): S4-S11.

Collin SM (2013). Folate and B12 in prostate cancer. Adv. Clin. Chem. 60: 1-63.

de Cássia Carvalho BR, da Costa DM, Cordeiro DE, Vieira AP, et al. (2012). Interaction of MTHFR C677T and A1298C, and MTR A2756G gene polymorphisms in breast cancer risk in a population in Northeast Brazil. Anticancer Res. 32: 4805-4811.
} 
Diakite B, Tazzite A, Hamzi K, Jouhadi H, et al. (2012). Methylenetetrahydrofolate reductase C677T polymorphism and breast cancer risk in Moroccan women. Afr. Health Sci. 12: 204-209.

Ergul E, Sazci A, Utkan Z and Canturk NZ (2003). Polymorphisms in the MTHFR gene are associated with breast cancer. Tumour Biol. 24: 286-290.

Ericson U, Sonestedt E, Gullberg B, Olsson H, et al. (2007). High folate intake is associated with lower breast cancer incidence in postmenopausal women in the Malmo Diet and Cancer cohort. Am. J. Clin. Nutr. 86: 434-443.

Gao CM, Kazuo T, Tang JH, Cao HX, et al. (2009). MTHFR polymorphisms, dietary folate intake and risks to breast cancer. Zhonghua Yu Fang Yi Xue Za Zhi. 43: 576-580.

Gao S, Ding LH, Wang JW, Li CB, et al. (2013). Diet folate, DNA methylation and polymorphisms in methylenetetrahydrofolate reductase in association with the susceptibility to gastric cancer. Asian Pac. J. Cancer Prev. 14: 299-302.

Gershoni-Baruch R, Dagan E, Israeli D, Kasinetz L, et al. (2000). Association of the C677T polymorphism in the MTHFR gene with breast and/or ovarian cancer risk in Jewish women. Eur. J. Cancer 36: 2313-2316.

Hosseini M, Houshmand M and Ebrahimi A (2011). MTHFR polymorphisms and breast cancer risk. Arch. Med. Sci. 7: 134-137.

Islam T, Ito H, Sueta A, Hosono S, et al. (2013). Alcohol and dietary folate intake and the risk of breast cancer: a casecontrol study in Japan. Eur. J. Cancer Prev. 22: 358-366.

Jiao Z and Li D (2013). Lack of association between MHTFR Glu429Ala polymorphism and breast cancer susceptibility: a systematic review and meta-analysis of 29 research studies. Tumour Biol. 34: 1225-1233.

Kim YI (2006). Does a high folate intake increase the risk of breast cancer? Nutr. Rev. 64: 468-475.

Koppen IJ, Hermans FJ and Kaspers GJ (2010). Folate related gene polymorphisms and susceptibility to develop childhood acute lymphoblastic leukaemia. Br. J. Haematol. 148: 3-14.

Lajin B, Alhaj SA, Ghabreau L and Alachkar A (2012). Association of polymorphisms in one-carbon metabolizing genes with breast cancer risk in Syrian women. Tumour Biol. 33: 1133-1139.

Le Marchand L, Haiman CA, Wilkens LR, Kolonel LN, et al. (2004). MTHFR polymorphisms, diet, HRT, and breast cancer risk: the multiethnic cohort study. Cancer Epidemiol. Biomarkers Prev. 13: 2071-2077.

Levi F, Pasche C, Lucchini F and La Vecchia C (2001). Dietary intake of selected micronutrients and breast-cancer risk. Int. J. Cancer 91: 260-263.

Lin HL, An QZ, Wang QZ and Liu CX (2013). Folate intake and pancreatic cancer risk: an overall and dose-response meta-analysis. Public Health 127: 607-613.

Lin J, Lee IM, Cook NR, Selhub J, et al. (2008). Plasma folate, vitamin B-6, vitamin B-12, and risk of breast cancer in women. Am. J. Clin. Nutr. 87: 734-743.

Liu Y, Zhou LS, Xu XM, Deng LQ, et al. (2013). Association of dietary intake of folate, vitamin B6 and B12 and MTHFR genotype with breast cancer risk. Asian Pac. J. Cancer Prev. 14: 5189-5192.

Maruti SS, Ulrich CM and White E (2009a). Folate and one-carbon metabolism nutrients from supplements and diet in relation to breast cancer risk. Am. J. Clin. Nutr. 89: 624-633.

Maruti SS, Ulrich CM, Jupe ER and White E (2009b). MTHFR C677T and postmenopausal breast cancer risk by intakes of one-carbon metabolism nutrients: a nested case-control study. Breast Cancer Res. 11: R91.

Nikbakht M, MalekZadeh K, Kumar JA, Askari M, et al. (2012). Polymorphisms of MTHFR and MTR genes are not related to susceptibility to childhood ALL in North India. Exp. Oncol. 34: 43-48.

Rossi E, Hung J, Beilby JP, Knuiman MW, et al. (2006). Folate levels and cancer morbidity and mortality: prospective cohort study from Busselton, Western Australia. Ann. Epidemiol. 16: 206-212.

Sangrajrang S, Sato Y, Sakamoto H, Ohnami S, et al. (2010). Genetic polymorphisms in folate and alcohol metabolism and breast cancer risk: a case-control study in Thai women. Breast Cancer Res. Treat. 123: 885-893.

Shrubsole MJ, Shu XO, Li HL, Cai H, et al. (2011). Dietary B vitamin and methionine intakes and breast cancer risk among Chinese women. Am. J. Epidemiol. 173: 1171-1182.

Ulrich CM (2005). Nutrigenetics in cancer research - folate metabolism and colorectal cancer. J. Nutr. 135: 2698-2702.

Vănner AS, Boiarskikh UA, Voronina EN, Selezneva IA, et al. (2010). Polymorphic variants of folate metabolizing genes (C677T and A1298C MTHFR, C1420T SHMT1 and G1958A MTHFD) are not associated with the risk of breast cancer in West Siberian Region of Russia. Mol. Biol. 44: 816-823.

Wu XY, Ni J, Xu WJ, Zhou T, et al. (2012). Interactions between MTHFR C677T-A1298C variants and folic acid deficiency affect breast cancer risk in a Chinese population. Asian Pac. J. Cancer Prev. 13: 2199-2206.

Yang D, Baumgartner RN, Slattery ML, Wang C, et al. (2013). Dietary intake of folate, B-vitamins and methionine and breast cancer risk among Hispanic and non-Hispanic white women. PLoS One 8: e54495.

Yu L and Chen J (2012). Association of MTHFR Ala222Val (rs1801133) polymorphism and breast cancer susceptibility: An update meta-analysis based on 51 research studies. Diagn. Pathol. 7: 171. 